\title{
Effects of Covid-19 Pandemic on the Welfare of the Maasai Girl Child in Narok County, Kenya
}

\section{Morompi Ole Masago}

Department of Curriculum Instruction and Education Management, Maasai mara university, Kenya

Sambu Alice

Department of Social Studies, Religion and Community Development, Maasai mara university, Kenya

Kweingoti G. Reuben

Department of Social Studies, Religion and Community Development, Maasai mara university, Kenya

Jebet Sheila

Department of Special Needs Education, Maasai Mara university, Kenya

Bakari Chaka

Department of Mathematics and Physical Sciences, Maasai mara university, Kenya

Kelele Joshua

Department of Social Studies, Religion and Community Development, Maasai mara university, Kenya

\section{Abstract}

The Maasai girl child is vulnerable to poor menstrual hygiene, teen pregnancies, early marriages, domestic violence and female genital mutilation (FGM). Schools had temporarily offered the girls a shelter towards these challenges. However, covid-19 pandemic led to indefinite closure of schools forcing the girls back home to the full glare of these predicaments. Additionally, there was fear of the health pandemic which had also affected the economy. This study aimed at examining how covid-19 pandemic had affected the welfare of the Maasai girl child in Narok county, Kenya. A crosssectional design of study was used. Data was collected using questionnaires and by observations. Descriptive analysis was used to analyze the data. The findings indicate that frustrations over lack of basic needs coupled with numerous domestic violence incidences caused the girls to engage in 'sex for 
sanitary towels'. 83.1\% of the girls did not use any sex protection means while majority of the rest used ineffective methods. FGM was at its peak as there was abundant time to practice it and less government interference. In conclusion, the Maasai girls' welfare was in dire need for external assistance. Government and non-governmental organizations (NGOs) should urgently intervene to rescue the Maasai girl child.

Keywords: Maasai girl child; covid-19 break; teen pregnancies; early marriages; Female Genital Mutilation

\section{Introduction}

\section{Background of Study}

The plight of the Maasai girl child has always been jeopardized by many factors (maasaigirlseducation.org., 2020). Most of these factors are integrated on the patriarchal Maa culture (Morompi et al., 2020; Morompi, 2018, Hodgson, 1999). Heavily laden traditions have negatively affected any form of civil progress to the Maasai girl child. Her education, employment, business or political ambitions are always pulled back by a web of patriarchal cultures and traditions. According to these traditions, her role is reserved in the kitchen and matrimonial bed. Here, she is destined to satisfy all her husbands needs, make and bring up children; without questioning. Her wife-count position is a non-issue as her husband can marry as many wives as his cattle can support.

The Maasai girl child does not actually belong to her family and is seen as a passer-by where she is exchanged for cattle from one clan to the next on maturity (maasaigirlseducation.org., 2020). Any girl above the age of 8 (beginning adolescence) is as good as mature. The decision to her marriage is solely bestowed on her father and elders (all male). The groom's age can range anywhere between a Moran (over 19 years) to that of a senior elder (over 70 years). It is actually not surprising for an 8-year old girl to wed a 90-year old Maasai elder. As a pre-requisite into marriage hood, all the fresh brides have to undergo female genital mutilation (FGM) (Muchene et al., 2018). Failure to undertake this rite leaves the uncircumcised bride with a lot of dishonor and very little respect in public. Menstrual health is perceived as a shameful act and never discussed in public (Pakdamana and Beina, 2014). The Maasai girl experiencing menstruation is expected to sought it on her own in secret using any material; hygienic or not (Pakdamana and Beina, 2014). Sex education is also rarely discussed between parents and the girl. The girl is expected to maintain utmost chastity without necessarily raising any matters on the same to her guardians. 
Although the Maasai have been rigid in accepting western civilization, formal education has gradually but surely encroached into Maasailand (Morompi and Kweingoti, 2018). The government and other non-governmental organizations have heavily invested in formal education through building leaning infrastructure and provision of teachers and other learning resources. The process has not been quite successful owing to the rigidity of their culture towards foreign civilization. Numerous efforts have been made by education stakeholders to persuade the custodians of the culture (elders) to allow their daughters to go to school (Morompi and Kweingoti, 2018). This is because formal education is perceived to be the savior that will free the Maasai girl child from her plight. Introduction of free primary education by the government in 2003 increased the enrollment rate of the girls by a significant margin. However, other issues, most linked to culture have ensured the completion and transition rate of the girls as they advance academically is very low.

Formal education has reduced some of these challenges faced by the Maasai girl child, community illiteracy and oppression. Most of the initial challenges such as teenage pregnancies, FGM and menstrual health matters reduced when the girls were taken to school. Enrollment of the girls in school kept them away from these matters (Korir et al., 2018) while increasing their level of understanding on the matters in a more rational manner. In school, the girls are actively engaged with curricular and cocurricular activities that keep their minds occupied thus avoiding these challenges (Archambault, 2017). School vacations slightly affect tis temporal relief from their challenges but to an insignificant margin.

The covid-19 pandemic led to indefinite closure of all learning institutions in Kenya. The learners were forced to go home until the pandemic was contained. The situation worsened with time and days became weeks which later became months. The challenges faced by the Maasai girl child which had taken so long to alleviate began re-manifesting themselves back. There was no more school to shelter the girls from teenage pregnancies, FGM and poor menstrual activities. Additionally, other social immoralities attributed to modern civilization and tourism such as drug and substance abuse and sexual immorality merged with the traditional vices to mount more misery onto the girls. As if this is not enough, economic hardships arising from covid-19 pandemic saw and increase in domestic violence which indirectly affected the girls. Finances for purchasing girls' necessities such as menstrual towels were thus out of priority as families used the meagre resources available to purchase food and pay for shelter. Economic frustrations also saw an increase in the rate of drug and alcohol abuse. Many guardians chose to use these commodities as a temporal relief to their problems. On the other hand, idleness resulting from mandatory staying at home with no meaningful learning increased the girls' exposure to drug abuse and sexual immoralities. 
This study aimed at assessing the social, psychological and economic impacts of covid19 pandemic on the welfare of the Maasai girl child in Narok county, Kenya. Narok county is one of the three counties in Kenya (alongside Kajiado and Samburu) with a large population of the Maasai people. It is a marginalized county with the Maa culture deeply rooted amongst most of its inhabitants.

\section{Research Methodology}

\subsection{Design of Study}

A cross-sectional research design was used for the study. This design was opted to enable the researchers determine the impacts of covid-19 on the welfare of Maasai girls at the epitome of the pandemic (the month of June, 2020). The month was suitable since a grace period of 3 months (since march) was sufficient for the challenges affecting the girls to manifest out. This was also the most unprecedented month of the pandemic in Kenya with most decisions anchored on the presidents' decision to be made on $6^{\text {th }}$ July, 2020. The economy was at its lowest and domestic violence cases had sharply increased. The study was conducted in Narok county (coordinates $1.1041^{\circ} \mathrm{S}, 36.0893^{\circ} \mathrm{E}$; figure 1). The county has the largest population of Maasai people in Kenya (Bussmann et al., 2006; Kenya National Bureau of Statistics, 2019). Data was collected using questionnaire guides and observation and descriptive statistics used to analyze it. The findings were presented in form of text, tables, quotes and graphs.

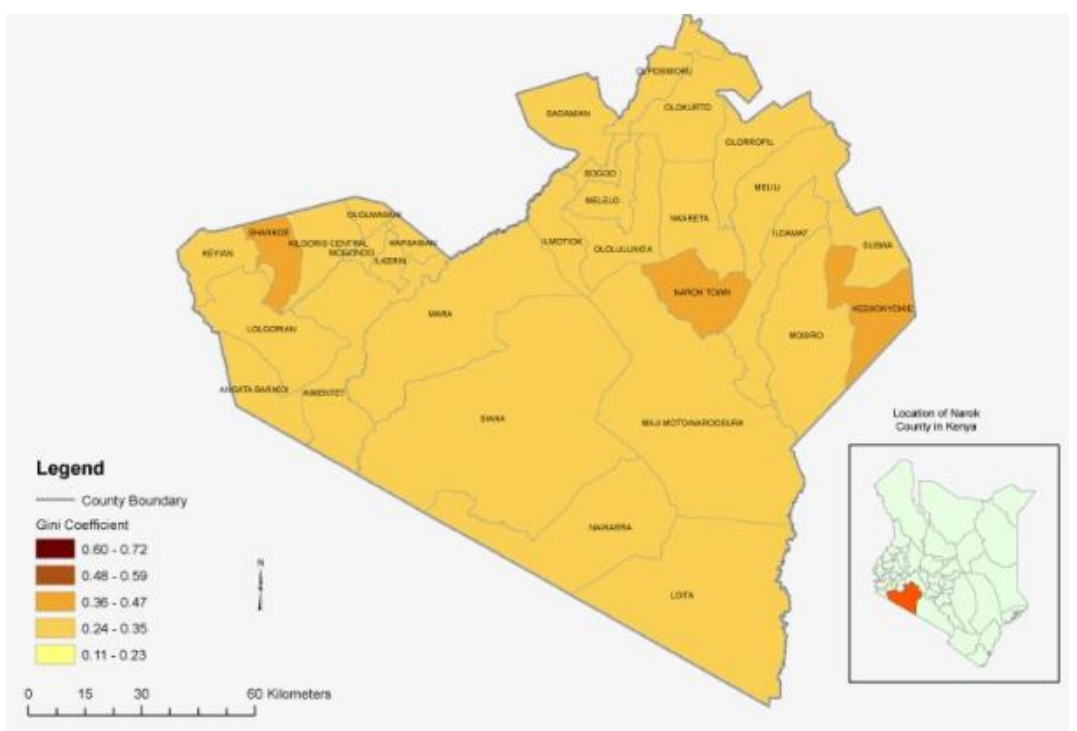

Figure 1: Map of Narok county, Kenya where the study was conducted.

Source: pngkey.com, (2020). 


\subsection{Sampling Techniques}

Random sampling was carried out throughout the county. The target population was all the Maasai school-going girls between the age of 12 to 18. This cluster was assumed to be mature enough to experience the challenges faced by the Maasai girl child. All the girls within this bracket were randomly picked as respondents. The method was preferred for its ability to sample a small representative group from a bigger population with limited bias. Any respondent could be taken from the main target population with equal probability.

\subsection{Sample size}

The target population of the girls in the county was very large and had to be narrowed down to a desirable size. The target population could not be wholly analyzed and was therefore reduced to 80 samples. The sample size was arrived at from Slovin's formulae (Statisticshowto.com, 2020) outlined in equation 1.

$n=\frac{N}{1+N\left(e^{2}\right)}$

Where, n-sample size, N-population size, e- Error term (5\%) based on 95\% confidence interval

The samples were spread out across the various wards in the county.

\subsection{Research questionnaires, interviews and observation guides used}

The study involved use of questionnaires guides and observation. The questionnaires were unstructured and had both open ended and closed research questions. The questionnaires were divided into 9 main sections i.e respondents biodata section, family, financial, academic, domestic, sexual life, personal and psychological, drugs and alcohol abuse and FGM information. The respondents were assigned the questionnaire guides and given a duration of 3 days to fill the data. During collection of the questionnaire guides, any interesting information that was not captured in the questionnaires was noted down at the back of the questionnaires guides Observations were made to assess some of the situations that could easily be noticed. There was no clear structure or number of research items in an observation guide but rather researchers' opinion on notable features of respondents.

\subsection{Validity and reliability of the research guides used}

Questionnaires were quite reliable since they were easy to administer and encouraged confidentiality thus, reducing biasness. They were subjected to the testretest reliability method to check for their consistency in results after a duration of 11 days. A group of 15 respondents (volunteers) was used. There was a similarity index of $63 \%$ in the results at the two instances of testing. Observation also ensured gathering of reliable data. The 15 respondents were also assigned with the same task and a 58\% similarity index observed. A face validity of the research guides was 
conducted by 4 volunteers. A pilot study was then conducted to determine the validity of the data collection instruments used. Each of the 110 initial distinct research questions in the questionnaire guide (excluding bio-data section) was assigned to 2 different respondents. In total, there were 220 respondents (volunteers). The data was then debugged and the minimum and maximum values recorded. After a critical analysis check, 15 questions were found to be confusing and leading. These questions were plucked out. The ultimate validity score was thus 95/110 (86.4\%) and the outcomes were found to strongly favor the use of these research guides.

\subsection{Data analysis}

The data collected was analyzed and presented using descriptive statistics. The data collected was analyzed using Ms Excel (2016). For the significance levels, a confidence level of $95 \%$ was used.

\section{Results and Discussions}

\subsection{Family information regarding the Maasai girls}

Majority (70.9\%) of the girls lived in a nuclear family set-up. Only $7.5 \%$ of the girls had been adopted and lived with their foster families while $21.6 \%$ of the girls in the county lived in an extended family set-up. The large proportion of nuclear families compared to extended families is partially attributed to western civilization (Ruggles, 2010; Chen et al., 2017). The traditional Maa culture consisted of most of the families living communally; in small clans (Mokgobi, 2014). These clans comprised of several extended families all originating from a common ancestor (Mokgobi, 2014). However, due to western civilization, these clans dispersed as individuals went further apart to seek for livelihoods. With regard to the girls' welfare, girls living in an extended family setup are likely to have their matters addressed quickly compared to those living in nuclear families. This is because in extended families, they have many peers and can front their needs as a group. On the other hand, there are more stakeholders in the form of cousins, mothers, aunties and grandmothers to address their issues compared to in a nuclear family. $64 \%$ of the nuclear families had both parents while $36 \%$ had only a single parent living with the girls. Out of the $36 \%$ of the families where the girls lived with a single parent, $95 \%$ of the single parent were their mothers. The girls' fathers did not live with their families because they were either deceased (9\%), worked far away (21\%) or lived with another spouse (71\%). The high proportion of fathers living with their younger spouses is attributed to the patriarchal Maasai culture which encouraged polygamy (Morompi, 2018; Hodgson, 1999). Some of the younger wives in question were school-going girls who were forcefully wedded. This detachment of girls to their fathers have negative impacts on the girls support as described by one of the girls in Naikarra, Narok south;

...my dad used to provide me with everything. He would pay all my school fees, buy me school uniform and get us enough food at home every day. However, since he married 
the younger wife, some of the necessities are no longer available. For example, my school uniform is worn out and my mother does not have enough money to buy me another one. Most of my colleagues make fun of me in school. My father no longer prioritize most of our basic needs...

The was an equal distribution in the number of male and female siblings in the girls' families as illustrated in figure 2 .

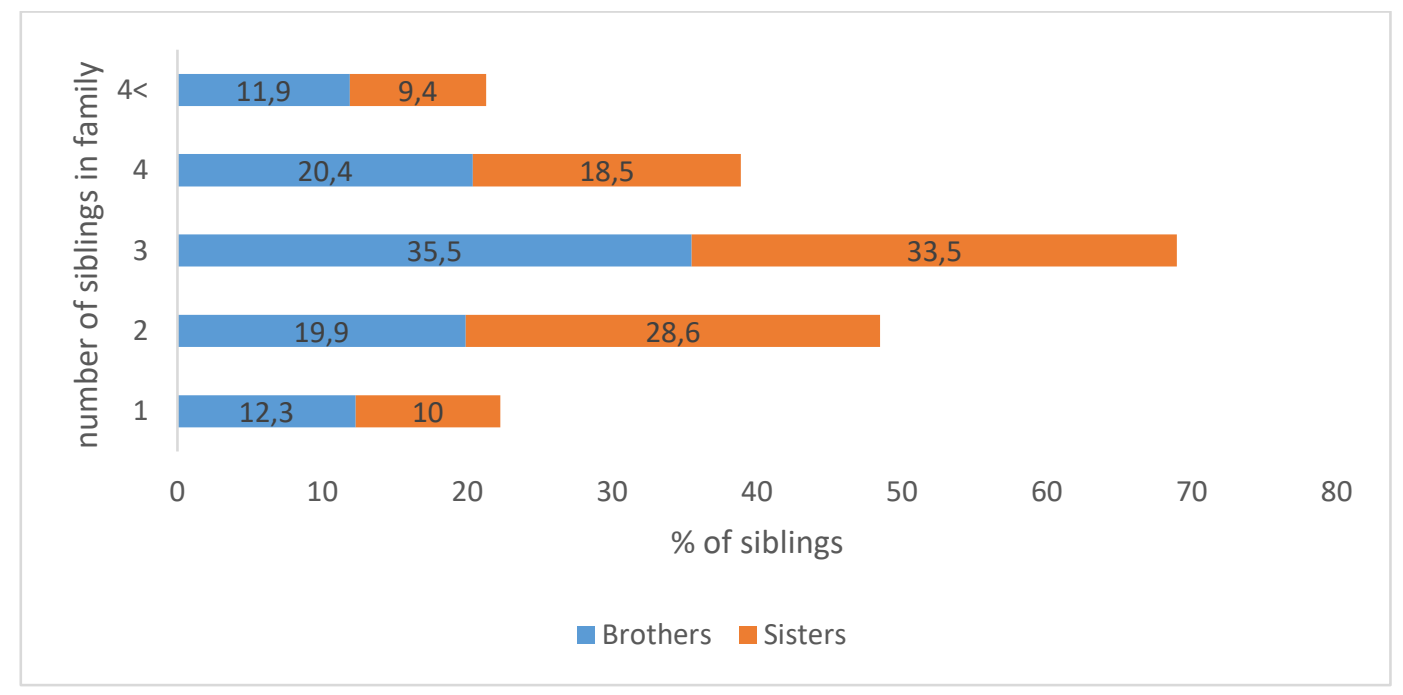

Figure 2: Distribution of number of siblings in the families of Maasai girl children

Majority of the girls had 3 brothers (35.5\%) and sisters (33.5\%). This implies that about a third of the girls lived in families consisting of 7 children. According to East (2010), the number of siblings can affect the welfare of girls in terms of provision. Girls with fewer siblings are likely to get more attention from their guardians (Hsueh and Gennetian, 2011). According to Olson et al., (2017), girls deserve more attention from their guardians compared to their male counterparts. A higher number of girls in the families thus imply less attention from the guardians. According to figure 2, the Maasai girl children had a relatively equal distribution in the number of male and female siblings. Therefore, there was no significant diversion in attention resulting from the gender of their siblings. About $69.9 \%$ of the families were monogamous while $30.1 \%$ were polygamous. The reduction in polygamous families from the conventional Maa culture is attributed to increase in western civilization. Some of the elements of western civilization such as western religion (in this case Christianity) strongly oppose polygamy. The attention for girls living in the polygamous families depended on the position of their mothers in the husbands rating (usually based on age). Girls whose mothers were the first wives had less attention compared to those whose mothers were the last wives. $59 \%$ of the polygamous families had 2 wives, $32 \%$ had 3 wives while $9 \%$ had more than 3 wives. The more the number of wives, the 
lesser the attention the girls received from their fathers. The girls living in polygamous and extended family set-ups faced more competition for attention and necessities due to the higher number of recipients as illustrated in table 1.

Table 1: The number of siblings of the Maasai girls living in polygamous and extended families

\begin{tabular}{llll}
\hline \multirow{2}{*}{$\begin{array}{l}\text { Number of } \\
\text { girls' siblings }\end{array}$} & \multicolumn{2}{l}{ \% of Maasai girls' siblings } \\
\cline { 2 - 4 } & $\begin{array}{l}\text { In polygamous } \\
\text { families }\end{array}$ & $\begin{array}{l}\text { In extended } \\
\text { families }\end{array}$ & $\begin{array}{l}\text { Those below 18 } \\
\text { years }\end{array}$ \\
\hline $1-5$ & 3.3 & 8.1 & 14.6 \\
$6-10$ & 20.2 & 15.3 & 56.3 \\
$11-15$ & 48.5 & 36.5 & 20.2 \\
$16-20$ & 28.0 & 29.9 & 8.9 \\
$20<$ & 0.0 & 10.2 & 0.0 \\
\hline
\end{tabular}

There was no significant difference in the distribution of siblings living in polygamous and extended families $(\mathrm{P}<0.05)$. From table 1, majority of girls living in extended and polygamous families had 11 to 15 siblings. This is significantly higher than the conventional 6 siblings from girls living in nuclear families $(P>0.05)$. About $96.7 \%$ of girls living in polygamous families had between 6 to 20 siblings. This is a very high number compared to the limited resources available for these families. Majority (56.3\%) of families with 6 to 10 girls had siblings who were below 18 years. This is a critical factor to consider because these are the siblings who are actively competing for attention and resources. For most of the Maasai families, siblings above 18 years are independent. For the male siblings, they are initiated into Moranhood (adulthood) and are expected to be actively engaging in their independent economic livelihoods (McCabe et al., 2014). Majority of female siblings above 18 years are expected to be married (Bobbitt-Zeher et al., 2018). There was literally no change in the patterns of the girls' family size due to covid-19 pandemic because its window was barely 3 months old.

\subsection{Domestic violence in the Maasai girls' families}

The number of domestic violence cases in Kenya increased during the covid-19 pandemic period (Odhiambo, 2020). The Maasai girl child was not exempted from these incidences. $49.7 \%$ of the girls confirmed that their guardians had engaged in domestic violence during the covid-19 pandemic period. The girls indicated that the incidences were quite horrible and would not love to experience them again. $28.5 \%$ of the incidences were minor and involved heated exchange of vulgar language and minor fights. $66.3 \%$ of the incidences were moderate and involved fights which led to

${ }^{1}$ Sibling population in girls living in an extended or polygamous family 
severe injuries. The incidences ended up with casualties in hospitals or dispensaries and other social effects to the family members. $5.2 \%$ of the incidences were extremely severe and lead to divorce and hospitalization of the guardians for more than 3 days. There was no death reported arising from the incidences. Covid-19 pandemic had increased the frequency of domestic violence incidences as illustrated in figure 3.

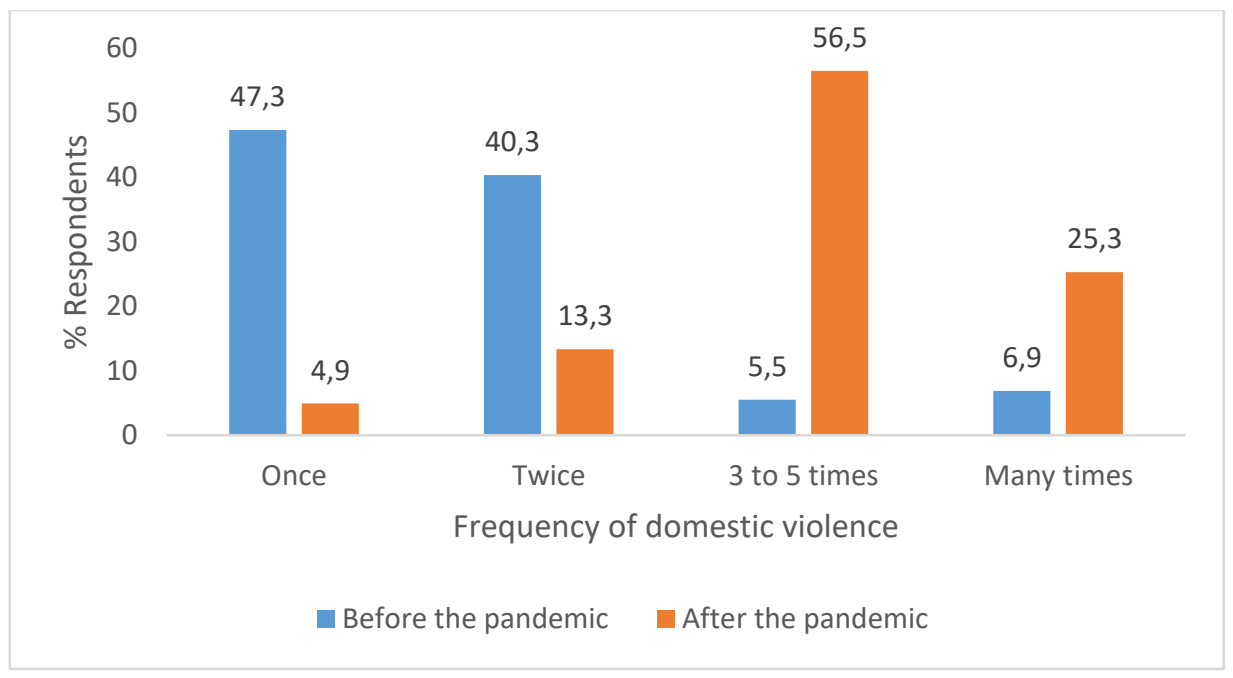

Figure 3: The frequency of domestic violence incidences in the girls' families

There was an upward surge in the number of incidences during the pandemic period. The surge might have been triggered by reduced monetary circulation as a result of the failing economy and an increase in contact time between family members. There is a higher probability of domestic violence when family members are together at home and there is little economic activity ongoing. The patriarchal role of the male guardians is put under trial if they stay at home and do not suffice the requirements of the family. This provokes their female counterparts leading to misunderstanding. If the misunderstandings are not controlled, then domestic violence results. Before covid-19 pandemic, most of the families where the Maasai girls belonged to had witnessed only 1 or 2 domestic violence cases. However, after the pandemic, 56.5\% of the families had witnessed violence 3 to 5 times while $25.3 \%$ of the families had witnessed violence more than 5 (numerous) times. Only $22 \%$ of these incidences were reported. The girls indicated that in most of the cases, their female guardians were on the receiving end. Very few would fight back. They were also expected not to report the incidence failure to which they would face severe consequences. The patriarchal Maasai culture allowed for wife battery as a method to instill discipline to Maasai women (maasaigirlseducation.org., 2020). The women were regarded as big children and could easily receive beatings when their husbands so wished. Out of the $22 \%$ incidences which were reported, in $46.5 \%$ of them no action was taken. $17.9 \%$ of the incidences led to police arrests while $35.6 \%$ of the cases were settled in the 
family by clan elders. The Maasai girls indicated that the clan elders always sided with their male guardians and justice was never served. These frustrating measures prompted their female guardians to persevere the incidences. Several factors contributed to the domestic violence incidences as illustrated in figure 4.

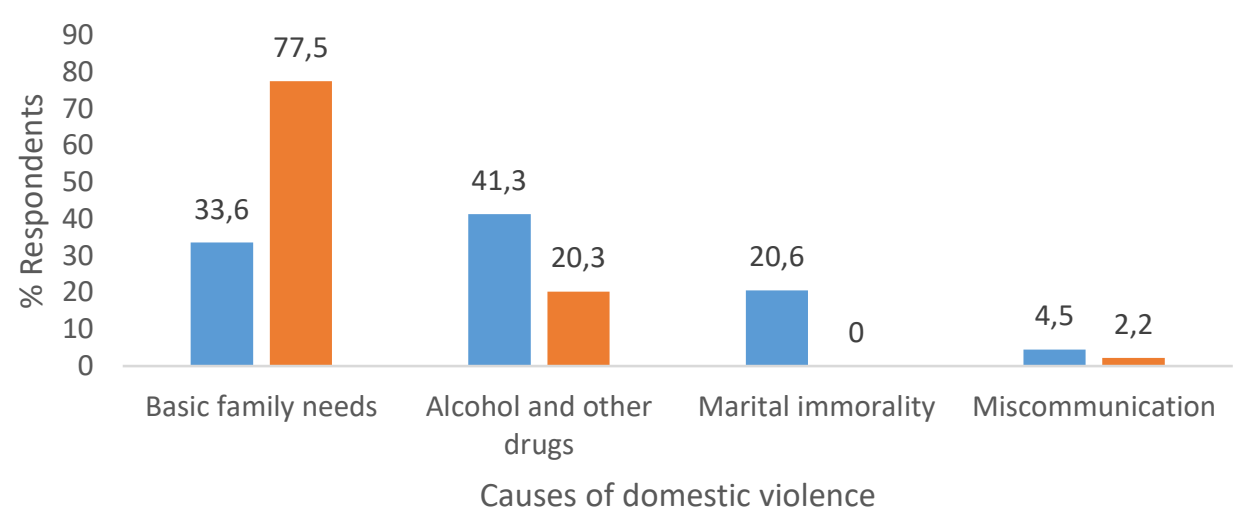

Before the pandemic $\quad$ After the pandemic

Figure 4: Causes of domestic violence incidences in the families of the Maasai girls

There was an increase in domestic violence arising from lack of provision of basin necessities such as food during the pandemic. This was fueled by the failing economy which led to reduced salaries and job losses. Some of the male guardians were frustrated by the situation and directed their anger onto their wives and children. In some cases, the female counterparts could not withstand insufficient provision of necessities by their male counterparts leading to violence. The number of violence incidences arising from alcohol and drugs as well as marital immorality had reduced because there was little money to engage in these activities. The incidences had a negative impact on the Maasai girls. Majority (68.5\%) of the girls whose guardians engaged in domestic violence indicated that they were undergoing depression and mental trauma. This is because of the consequences caused by the violence incidences and lack of harmony in their families. $15.7 \%$ of the girls indicated that the violence worsened the provision of necessities in their family. $8.2 \%$ of the girls had physical challenges resulting from trying to separate their fighting guardians or being battered together with their mothers in the incidences. $5.2 \%$ of the girls' academic performance were affected because they could not concentrate properly with their studies. Covid-19 pandemic had thus fueled the number of domestic violence incidences thus affecting the welfare of the Maasai girls in several ways.

\subsection{Sexual life, teen pregnancies and early marriages faced by the Maasai girls}


Only $21.5 \%$ of the Maasai girls admitted to having sex education with their guardians at home. All the rest of the girls indicated that the issue was considered shameful and their guardians avoided it in all possible ways. The girls indicated that their guardians expected them to learn about sex education in school and with their peers. According to the Maasai traditions, sex education was taught by the girls' mothers and elderly women (Graamans et al., 2019). However, this custom seems to have gradually eroded with contemporary social ethics as a result of western civilization. A deeper insight into the sex education sessions revealed that the talks were dominated by threats to the girls if they engaged with intimate relationships with boys. One of the girls narrates;

...it is always a threats session. My mother always insists that I am not to be seen talking to boys. She says that if I allow them to touch or play with me, I will become pregnant and it will humiliate her. This are the same lines used over and over every time...

The rest of the girls $(78.5 \%)$ indicated that they learn sex education from their teachers, elder siblings and friends. With their schools closed as a result of covid-19 pandemic, the sessions were solely left to their elder siblings and friends. However, most of the girls indicated that learning it from their friends was more comfortable. This creates chances of misleading advices and bad peer influence which can lead to sexual immoralities (Widman et al., 2016). Only 31.4\% of the girls' guardians were concerned with the menstrual health of their daughters. The rest always turned a blind eye to it and expected the girls to take care of their menstruation privately and in their own capacity. $84.3 \%$ of the concerned guardians were their mothers (or female guardians) while $1.5 \%$ were their male guardians. $3.6 \%$ of the girls indicated that they had both their guardians being concerned with their menstrual health while $10.6 \%$ indicated that their siblings assisted were concerned about it. This category of girls received support both psychologically, being provided with menstrual towels and exemptions from tasking duties during their periods. Provision of sanitary towels was the most common support given to the girls as indicated in table 2 .

Table 2: How the Maasai girls get their sanitary towels during menstrual periods

Method used by guardians to provide sanitary

$\%$ respondents

towels to the Maasai girls

Buy in bulk for the girls to collect when they

4.3

require them

Buy when needed by the girls 9.9

Give money to buy in bulk

0.5

Give money to buy when needed

4.2

Not concerned about it

Get the towels from friends and neighbors

22.5

Improvise using local fabric materials

19.3 
From table 2, it is evident that most of the girls had been neglected by their guardians as far as their sexual health is concerned. Only $18.9 \%$ of the guardians provided the towels. $39.3 \%$ of the guardians were not concerned with provision of sanitary towels while $22.5 \%$ of the girls obtained the towels from their friends and neighbors. One of the girls confessed that she finds it shameful to ask for the towels from her neighbors and currently obtain it from her friend (boyfriend). However, the towel is not provided freely and she has to 'pay for it' at a later date when she is 'safe to pay'. This leaves the girl vulnerable to other sexual immoralities. $22.3 \%$ of the girls indicated that covid-19 pandemic had altered the trend in provision of sanitary towels negatively. There were lesser guardians providing the towels because hard economic times had significantly reduced the provision of these necessities. The meagre earnings by the guardians were directed towards basic necessities such as food. This in turn increased the proportion of girls seeking for the towels from their friends (and boyfriends) thus exposing them to other sexual immoralities. One of the class 6 girls narrates;

... before the pandemic, my mother would give me money to purchase sanitary towels when I had my periods. Nowadays she doesn't have any money for the same. I have no option but to ask it from my boyfriend. In return, I have to sleep with him when the period is over. I do not like it but I don't have any other option.

$64.5 \%$ of the girls admitted to having a boyfriend. The girls argued that it was a contemporary issue to have one and lack of one led to jeers and criticism by their colleagues. Those without boyfriends (35.6\%) gave various reasons for their choices as illustrated in figure 5a. $36.3 \%$ of the girls who did not have boyfriends indicated that they were not concerned with the relationships at the moment. Majority of them were in their primary school level. It is therefore likely that they had not been subjected to a lot of peer pressure by their colleagues. The strictness of their guardians and teachers $(25.2 \%$ and $3.1 \%$ respectively) were also key in preventing the girls from having intimate relationships with boys. According to traditional Maasai culture, guardians were responsible for the moral upbringing of their children (Lawson et al., 2014). It was therefore their responsibility to ensure that their girls did not indulge in intimate relationship with boys before they were of the right age. However, moral degradation of this custom and contemporary social immoralities have reduced this norm. This has led to more intimate relationships amongst the girls. About $21.3 \%$ of the girls indicated that they were focusing on their academics for the time being and perceived intimate relationships with boys as a barrier to their studies. Only $2.7 \%$ of the girls indicated that they were yet to be approached by a boy for an intimate relationship. There was an increment in the incidences of the girls first meeting with boys with their ages up to after 15 years. The climax of these incidences

${ }^{1}$ Provision of sanitary towels for the girls by their guardians 
was between 14 to 15 years. About $72.3 \%$ of the girls in a relationship first met their boyfriends between 14 years and 17 years (figure 5b). Majority of the girls were either in class 8 or in their secondary school level. This is the prime age of their adolescence age. According to (Price et al., 2016), many girls are susceptible to intimate relationships at this age bracket. Most of the girls in this age bracket are in their secondary schools (some boarding) and the covid-19 pandemic school closure might have catalyzed their incidences of meeting with boys at home. A good proportion of the girls attended schools away from their hometowns (majority being single-gender boarding schools). The girls are thus deprived any chance of encountering with boys and are excited during holidays when they can finally meet with boys. The pandemic thus provided them with an excellent opportunity to satisfy this desire. There was a lower magnitude of girls first meeting their boyfriends beyond 18 years.

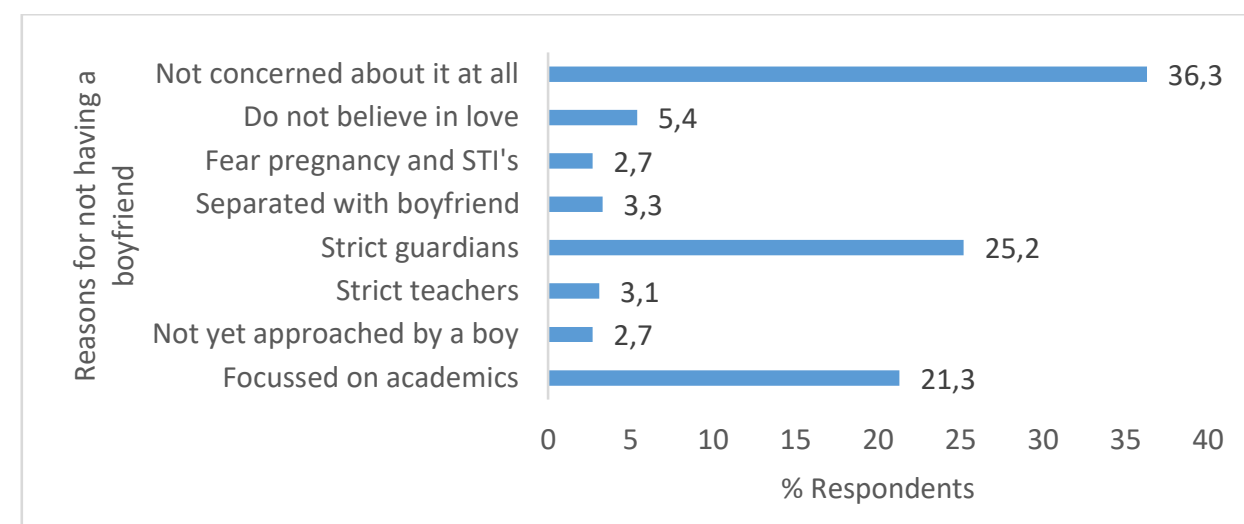

(a) 


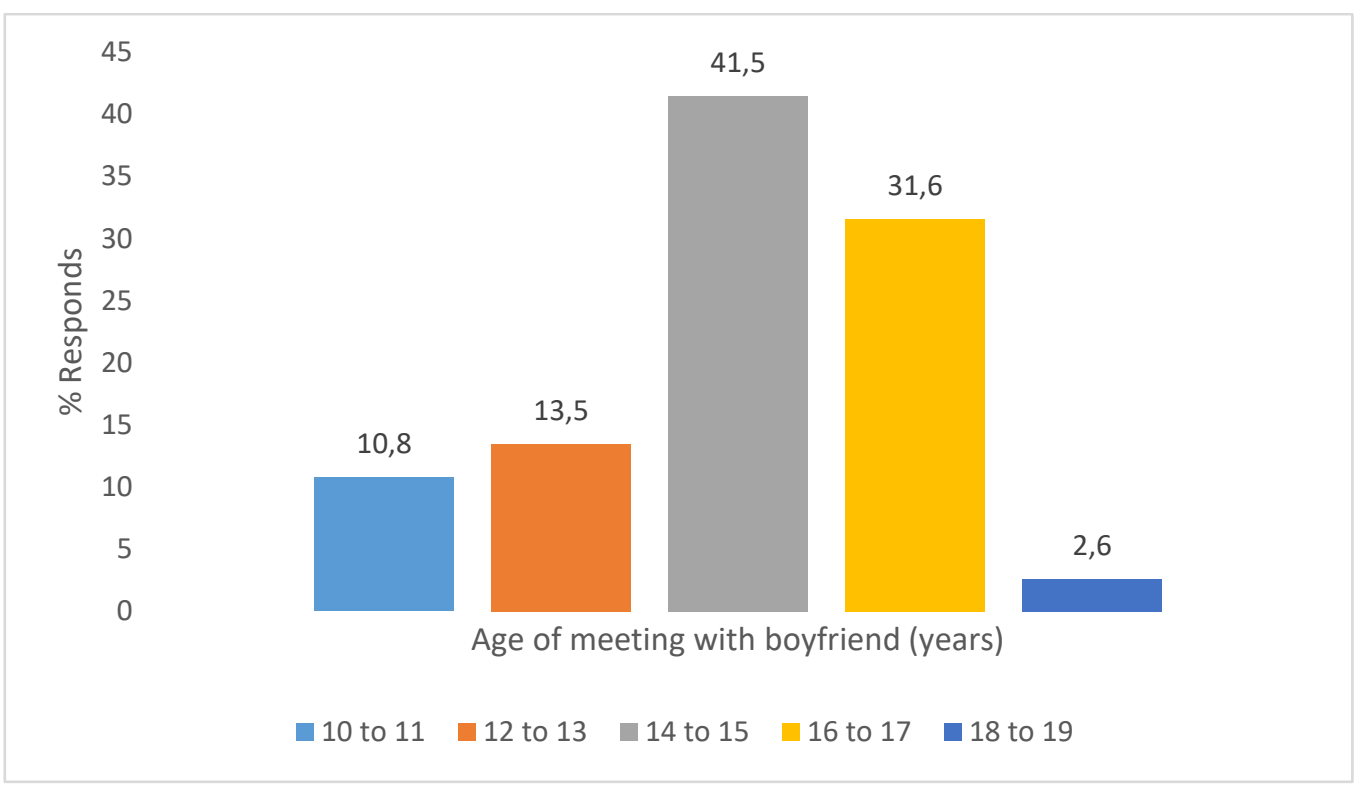

(b)

Figure 5: Reasons for not having boyfriends (a) and the age when the Maasai girls with boyfriends first met (b)

The girls met with their boyfriends through different people. About $39.4 \%$ of the girls had met their boyfriends though their friends. These friends also had boyfriends and pressurized their friends to join them. The prolonged stay at home owing to the pandemic increased interaction of girls with their friends and by extension more first engagements with boys. $29.2 \%$ of the girls first met their boyfriends through social media platforms while $28.6 \%$ of the girls had met in their respective schools. Only $2.7 \%$ of the girls had met their boyfriends through their relatives. There was a high correlation of the platforms of meeting and the people aware of these relations. 22.3\% of the girls' guardians were aware of their daughters' relationships and even supported them. Only $21.5 \%$ of the relationships were kept secretly between the girls and their boyfriends. $60.3 \%$ of the girls were actually remorseful that covid-19 pandemic had interrupted their relationships. The girls indicated that they could not freely see their boyfriends as was the case previously. They only interacted with the boys through social media, phone calls and text messages.

About $69.3 \%$ of the girls attested to having sex with their boyfriends. These incidences were triggered by peer pressure as well as quests by the girls to be given certain favors such as purchase of confections, credit cards and sanitary towels. In return, the girls had nothing else to offer other than sex. Majority of the girls indicated that the frequency of the incidences had increased during the pandemic period because they were in dire need of money to purchase their necessities. The period 
between first meeting and sexual intercourse of the girls with their partners is illustrated in figure 6 a.

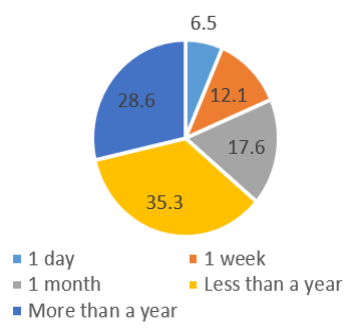

a)

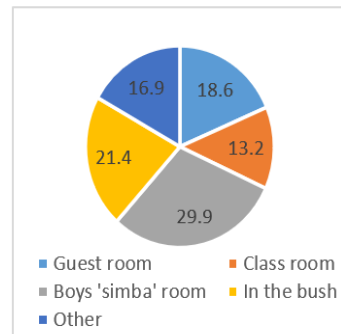

- Other

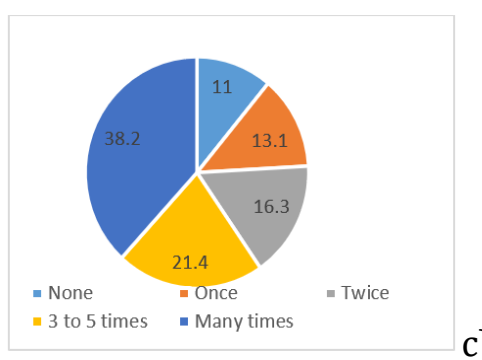

b)

Figure 6: Duration taken by Maasai girls between first encounter with their boyfriends and sexual intercourse (a), the venue of the first intercourse (b) and the consecutive number of intercourse sessions thereafter (c).

There was a relatively little amount of time for teen courtship between the first instance when the girls met their boyfriends and sexual intercourse. Only $28.6 \%$ of the girls could persevere for over a year without sexually engaging with their partners. The hurried consent to engage in the vice was informed by the demands of their boyfriends to re-pay favors done as narrated by one of the girls;

...I had no intentions to break my virginity this year. However, after the pandemic struck, my guardians could no longer provide sanitary towels for me. I therefore turned to my boy friend for provision of the towels who accepted. It was then that he begun asking me to sleep with him as a reward for providing the towels. I had no option but to concur.

The duration between first engagement and sexual intercourse between the girls and their boyfriends was found to be alarmingly low. Though this window is relative, there should be a grace period of adequate time before the two can engage in intercourse (Mishori et al., 2019). Morans' 'Simba' room is the house that a Maasai boy is given after initiation. This is intended to minimize interactions with their guardians (especially mothers) and siblings which can lead to taboos (Hodgson, 1999). This rooms were the most exploited (29.9\%) in having sexual intercourse with the girls (figure 6b). This is because they have a lot of privacy in the Manyatta homesteads and are out of reach to other members of the homestead (Hodgson, 1999). $21.4 \%$ of the girls had intercourse in the bush. This venue was preferred for being cheap and reliable to both parties involved. The venue is opportune when the boys do not have a 'Simba' and have no money to rent a guest room. $16.9 \%$ of the boys afforded to take their girls to restaurants and guest rooms. This was a relatively more dignified venue compared to bushes and classroom (used by $13.2 \%$ of the girls). 
Once their virginity was lost, there was no stopping the girls from continuing with the vices; it seemed (figure 6c). This is because more than half (59.6\%) of the girls had engaged in the vice more than thrice after the first incidence. Only $11 \%$ of the girls had not had intercourse with their partners after the first incidence. The high frequency of sexual intercourse incidences by the girls indicate loose morals and severe need for their necessities by the girls. As the pandemic era is prolonged, provision of necessities such as sanitary towels for the girls' use is also prolonged thus increasing more chances of the vices. $45.6 \%$ of the girls indicated that there were other parties aware of these vices other than themselves and their partners. According to the girls, almost all those aware of their intimate relationship with their partners were also aware of the vices (including their female guardians). Luckily enough, only $21.5 \%$ of the girls had engaged in the vice with more than one partner. All the other respondents had maintained their initial partners. A more alarming statistics is the number of girls who engaged in intercourse without any protection (83.1\%). Only $16.9 \%$ of the girls used protection during the incidence. This figure paints a very dark image of the girls when schools will be re-opened after the pandemic. The probability of most of the girls getting pregnant and ceasing school is quite high. The rest of the girls used various means to protect themselves from becoming pregnant or contracting STIs as illustrated in figure 7 (from their own perspective of protection methods). It is indeed sad to realize that majority (64.3\%) of the girls believed and actually used withdrawal tactic as an effective method of preventing unwanted pregnancies and STIs. The method is actually very ineffective in preventing either of the situations (Jones et al., 2014). The girls defended this tactic by indicating that they used it when they were in their safe menstrual days. $19.1 \%$ of the girls using prevention methods used condoms during the incidences. All the rest used medicinal compounds such as e-pills (5.6\%), injections (5\%) and traditional pharmacological concoctions (5.6\%). The concoctions were praised to be quite effective in controlling menstrual cycles. Several indigenous Maasai herbs have previously been used as phytochemicals in ethnomedicine (Bussmann et al., 2006; Omara, 2020). However, the exact efficiency of these prevention methods can only be determined later on when the girls start experiencing pregnancy related complications. 


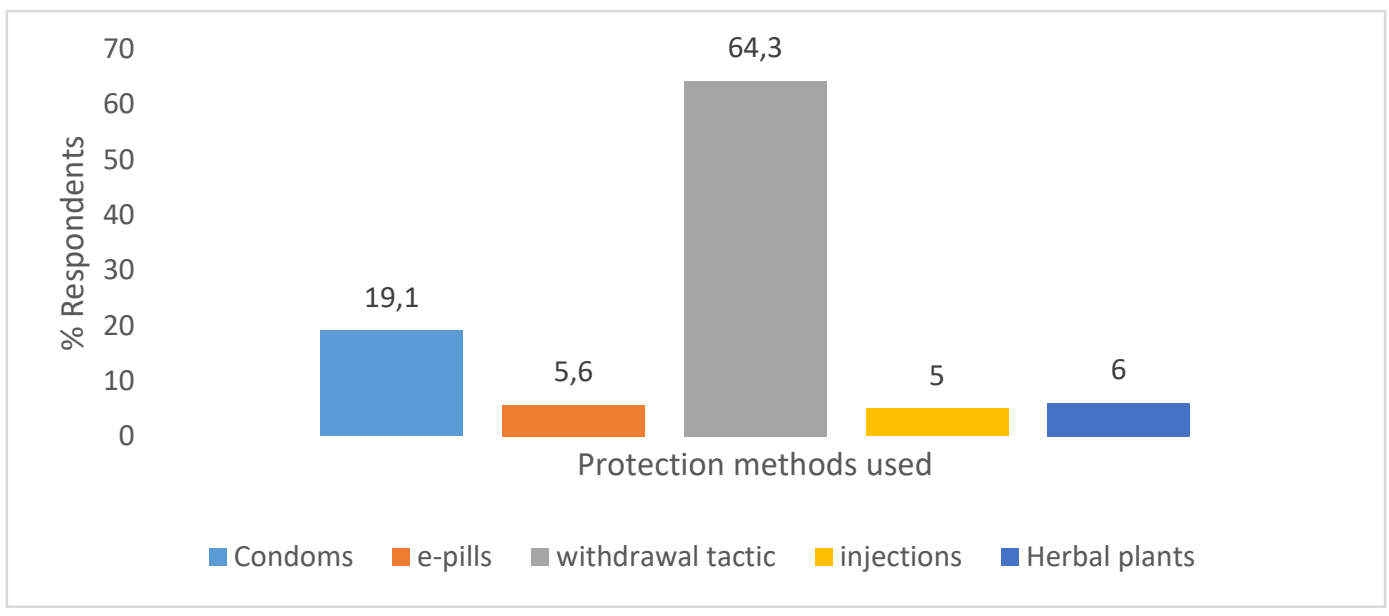

Figure 7: Some of the alleged prevention means as per the Maasai girls' belief and usage

$14.5 \%$ of the girls sampled indicated that they already had children. Almost all (91.6\%) of them had only a single child. The rest (8.4\%) had 2 children. $69.3 \%$ of these girls conceived between the age bracket of 16 to 19 years. This can be justified by the high number of girls getting boyfriends between 15 to 16 years (figure 5) and the short grace period between first engagement and sexual intercourse (figure 6a) as well as the low number of girls using effective birth control methods. $24.2 \%$ of the girls conceived within the age bracket of 13 to 15 years while the rest (6.5\%) conceived with 12 or less years. The teen pregnancies in question are those resulting from sexual intercourse before covid-19 pandemic. From the above findings it is almost guaranteed that the number of teen frequency will shoot within a few months. $71.5 \%$ of the girls with a child had less than 18 years. The distribution of teen mothers from the girls' school and villages is illustrated in table 3.

Table 3: Distribution of teen mothers in the Maasai girls' school and villages

\begin{tabular}{lll}
\hline Distribution of number of teen & \% Respondents \\
\cline { 2 - 3 } mothers & In the girls' school & In the girls' village \\
\hline $1-5$ & 10.1 & 0.7 \\
$6-10$ & 20.3 & 13.1 \\
$11-15$ & 36.4 & 29.9 \\
$>15$ & 33.2 & 56.3 \\
\hline
\end{tabular}

From table 3, most of the schools had more than 11 teenage mothers. Almost a third of the girls (33.2\%) indicated their schools had more than 15 teenage mothers. The

1 Distribution of Maasai teen mothers in the girls' schools and villages 
situation was worse in the girls' villages whereby more than half (56.3\%) of the girls attested to there being more than 15 teenage mothers in their villages. The tendency towards more teenage mothers in the girls' village was skewed towards the higher end. Actually, only $0.7 \%$ of the girls indicated there were 1 to 5 teenage mothers. The statistics in table 3 are those indicating the pre-existing teen mothers during the pandemic. From the findings in figures 5, 6 and 7, the number of teenage mothers is likely to be very high within a short period of time. Only $44.6 \%$ of the girls are able to resume their learning after conceiving. All the rest (55.4\%) are confined to their marital homes and cease learning henceforth. This figures project lower school transition from one academic level to the next when learning will proceed normally.

\subsection{Effect of the pandemic on FGM of the girls' welfare}

$95.0 \%$ of the girls were well aware of FGM through various people. The girls indicated that the vice had been practiced for a long time. Numerous efforts by the government and non-governmental organizations (NGOs) and other social bodies in curbing the menace fell on deaf ears. The residents of the county were determined to guard their culture with all its elements (good or bad). It was therefore very difficult to persuade the residents that FGM was bad. Girls who had not been initiated were regarded with little honor and considered unsuitable for marriage. $45.1 \%$ of the girls first heard about FGM through their guardians. The girls indicate that their guardians had always prepared them of being initiated psychologically by telling them its merits since they were young children. The girls then grew up knowing that initiation was mandatory and a good practice. Other girls first heard about FGM through NGOs (15.3\%) and in school through their teachers $(13.1 \%)$.

The girls indicate that these sources painted the tradition as a bad practice. Most of the NGOs (such as World Vision) were against FGM and would go an extra mile in rescuing girls who had been initiated (28toomany.org, 2013). The girls would be enrolled in boarding schools which had a collaboration with the NGOs. The teachers in those schools were tasked to preach against the vice by all possible means. $6.9 \%$ of the girls heard about FGM from their siblings while $19.6 \%$ of the girls knew about it from their friends. This campaigns and awareness measures were not possible since covid-19 pandemic struck since most of the learning institutions were closed.

$62.1 \%$ of the girls had undergone FGM. All the girls initiated indicated that they had been forced to undertake the initiation. Their guardians and relatives had collaborated in ensuring that they were circumcised. Most of the girls attested that the experiences were quite horrible and would not wish their loved ones to undertake such ordeals in future. Some of their peers whom they were to be initiated together had ran away never to return back to their homesteads. The girls further indicated that $63.5 \%$ of their friends, siblings and relatives had also undertaken the rite. The distribution of number of Maasai girls in the same village who had undergone FGM is illustrated in table 4. 
The number of girls undertaking FGM after covid-19 had sharply risen. This corresponded with more free time at home and less intrusion of the culture by formal education and NGOs. As a result, most of the guardians took the advantage and ensured their girls were initiated. Limited movement of people (especially from foreign nations) ensured that the custodians of the culture could practice their norms with little interference. This ensured the population of girls being initiated was skewed towards the higher end. Before the pandemic, most of the girls' village-mates (39.9\%) had 1 to 20 girls initiated. After the pandemic, the majority (63.6\%) had more than 60 girls per village initiated.

Table 4: Distribution of number of Maasai girls who had undertaken FGM per village

\begin{tabular}{lll}
\hline $\begin{array}{ll}\text { Number of girls who have } \\
\text { undertaken FGM per }\end{array}$ & \multicolumn{2}{l}{ Respondents (\%) } \\
\cline { 2 - 3 } village & Before covid-19 & After covid-19 \\
\hline $1-20$ & 39.9 & 8.7 \\
$21-40$ & 38.7 & 12.3 \\
$41-60$ & 16.4 & 15.4 \\
$>60$ & 5.0 & 63.6 \\
\hline
\end{tabular}

The girls confirmed that the local administrators had been trying to fight FGM but with very little success. Only $4.1 \%$ of the culprits involved had been arrested (according to the girls). All the others had gone free and any case involving the administrators had been withdrawn by one reason or the other. $12.3 \%$ of the girls agreed that the local administrators had succeeded in educating the local community against the vice. However, $84.5 \%$ of the girls indicated that the local administrators did not put any significant effort to curb FGM. The girls indicated that the administrators were bribed to ensure that the rites proceeded on without any hitch. Only pressure from their external supervisors at county or regional level would make them stop the vice. This would be done for a little time after which they would again relax their restrictions and allow FGM to proceed. Since covid-19 pandemic struck, there was fewer supervision from their seniors. This gave more room for the administrators to relax thus enhancing FGM practice.

\section{Conclusions}

Since covid-19 pandemic struck, most of the daily norms and lifestyles of Maasai girl children changed. The girls' guardians' livelihoods were significantly reduced increasing cases of domestic violence $(\mathrm{P}>0.05)$. The number of domestic violence had sharply risen amongst the girls' guardians. There was a higher engagement in fornication due to idleness and desire for the girls to have necessities. 'Sex for menstrual towels' was a common phenomenon by the girls. $71.5 \%$ of the girls did not use any protection during intercourse while $64.3 \%$ of those who did used 
'withdrawal' method. This casts a looming health and education pandemic once school reopen with numerous teen pregnancies and early marriages in waiting. Academic enrollment and transition through the classes are also heavily challenged. $58.3 \%$ of the girls confirmed that they were indeed stressed up. $21.1 \%$ of the girls engaged in various forms of alcohol and drug abuse. $62.1 \%$ of the girls had undergone FGM and the number was sharply increasing during the pandemic period.

\section{Recommendations}

The local administrators should tighten their grips towards immorality and some of the injustices affecting the girls. Parents should also come up with amicable means to resolve conflicts away from their children. Governmental and NGOs should also move with speed to ensure the welfare of the girls are well taken care of.

\section{Acknowledgements}

The authors wish to sincerely thank all those who participated in this study.

Declaration of Interests

'None'.

\section{Funding Sources}

This research did not receive any specific grant from funding agencies in the public, commercial, or not-for-profit sectors.

\section{Data Availability Statement}

All the data used in this study is enclosed within the manuscript and any supplementary sheets attached.

\section{References}

[1] 28toomany.org, (2013). Country profile: FGM in Kenya, May 2013. Retrieved from

https://www.28toomany.org/static/media/uploads/Country\%20Research \%20and\%20Resources/Kenya/kenya_country_profile_v3_(july_2017).pdf Accessed on $2^{\text {nd }}$ September, 2020.

[2] Bobbitt-Zeher, D., Downey, D. B., \& Merry, J. (2016). Number of Siblings During Childhood and the Likelihood of Divorce in Adulthood. Journal of family issues, 37(15), 2075-2094. https://doi.org/10.1177/0192513X14560641

[3] Bussmann, R. W., Gilbreath, G. G., Solio, J., Lutura, M., Lutuluo, R., Kunguru, K., Wood, N., \& Mathenge, S. G. (2006). Plant use of the Maasai of Sekenani Valley, Maasai Mara, Kenya. Journal of ethnobiology and ethnomedicine, 2, 22. https://doi.org/10.1186/1746-4269-2-22 
[4] Bussmann, R. W., Gilbreath, G. G., Solio, J., Lutura, M., Lutuluo, R., Kunguru, K., Wood, N., \& Mathenge, S. G. (2006). Plant use of the Maasai of Sekenani Valley, Maasai Mara, Kenya. Journal of ethnobiology and ethnomedicine, 2, 22. https://doi.org/10.1186/1746-4269-2-22.

[5] Caroline S. Archambault (2017) 'The pen is the spear of today': (re)producing gender in the Maasai schooling setting, Gender and Education, 29:6, 731-747, DOI: 10.1080/09540253.2016.1156061

[6] Chen, F., Bao, L., Shattuck, R. M., Borja, J. B., \& Gultiano, S. (2017). Implications of Changes in Family Structure and Composition for the Psychological Well-Being of Filipino Women in Middle and Later Years. Research on aging, 39(2), 275-299. https://doi.org/10.1177/0164027515611181

[7] East P. L. (2010). Children's Provision of Family Caregiving: Benefit or Burden?. Child development perspectives, 4(1), 10.1111/j.17508606.2009.00118.x. https://doi.org/10.1111/j.1750-8606.2009.00118.x

[8] Graamans, E., Ofware, P., Nguura, P., Eefje, S. \& Wouter ten, H. (2019) Understanding different positions on female genital cutting among Maasai and Samburu communities in Kenya: a cultural psychological perspective, Culture, Health \& Sexuality, 21:1, 79-94, DOI: $10.1080 / 13691058.2018 .1449890$

[9] Hodgson, D. (1999). "Once Intrepid Warriors": Modernity and the Production of Maasai Masculinities. Ethnology, 38(2), 121-150. doi: $10.2307 / 3773979$

[10] Hsueh, J., \& Gennetian, L. A. (2011). Welfare policies and adolescents: exploring the roles of sibling care, maternal work schedules, and economic resources. American journal of community psychology, 48(3-4), 322-340. https://doi.org/10.1007/s10464-011-9423-4

[11] Jones, R. K., Lindberg, L. D., \& Higgins, J. A. (2014). Pull and pray or extra protection? Contraceptive strategies involving withdrawal among US adult women. Contraception, 90(4), 416-421. https://doi.org/10.1016/j.contraception.2014.04.016

[12] Kenya National Bureau of Statistics (2019). 2019 Kenya Population and Housing Census Volume I: Population by County and Sub-County. Retrieved from https://www.knbs.or.ke/?wpdmpro=2019-kenyapopulation-and-housing-census-volume-i-population-by-county-and-subcounty. Accessed on 23rd July, 2020.

[13] Korir, E., Okwara, F. N., \& Okumbe, G. (2018). Menstrual hygiene management practices among primary school girls from a pastoralist community in Kenya: a cross sectional survey. The Pan African medical journal, 31, 222. https://doi.org/10.11604/pamj.2018.31.222.13521

[14] Lawson, D. W., Borgerhoff Mulder, M., Ghiselli, M. E., Ngadaya, E., Ngowi, B., Mfinanga, S. G., Hartwig, K., \& James, S. (2014). Ethnicity and child 
health in northern Tanzania: Maasai pastoralists are disadvantaged compared to neighbouring ethnic groups. PloS one, 9(10), e110447. https://doi.org/10.1371/journal.pone.0110447

[15] maasaigirlseducation.org. (2020). The life of a Maasai woman/ Maasai Girls Education Fund. Retrieved from http://maasaigirlseducation.org/the-need/the-life-of-a-maasai-woman/ Accessed on $2^{\text {nd }}$ September, 2020.

[16] Masago, J. 0. \& Kweingoti, R. G. (2018). Education as a goldmine in Africa: A case study of Eastern Africa. Academic Research Insight Journal, $1(1), 30-45$

[17] McCabe, J. T., Smith, N. M., Leslie, P. W., \& Telligman, A. L. (2014). Livelihood Diversification through Migration among a Pastoral People: Contrasting Case Studies of Maasai in Northern Tanzania. Human organization, 73(4), 389-400.

https://doi.org/10.17730/humo.73.4.vkr10nhr65g18400

[18] Mishori, R., Ferdowsian, H., Naimer, K., Volpellier, M., \& McHale, T. (2019). The little tissue that couldn't - dispelling myths about the Hymen's role in determining sexual history and assault. Reproductive health, 16(1), 74. https://doi.org/10.1186/s12978-019-0731-8

[19] Mokgobi M. G. (2014). Understanding traditional African healing. African journal for physical health education, recreation, and dance, 20(Suppl 2), 24-34.

[20] Morompi, O.M. (2018). Tourism Related Socio-Economic Activities and Pupils Academic Performance in the Kenya Certificate of Primary Education: In Narok West Sub County, Kenya, Kenya Education Research Database. Retrieved from http://kerd.ku.ac.ke/123456789/1560 Accessed on 2nd September, 2020.

[21] Morompi, O.M., Walingo, M., Osano, A., Bulitia, G. and Bakari, C. (2020) Impacts of neglecting African Traditional Environmental Conservation Practices and education on the environment: A Case of the Maasai People of Narok County, Kenya. International Journal of Innovative Research in Science, Engineering and Technology (IJIRSET), Vol 9(4). e-ISSN: 2319-8753, p-ISSN: 2320-6710:pg.2660-2669

[22] Muchene, K. W., Mageto, I. G., \& Cheptum, J. J. (2018). Knowledge and Attitude on Obstetric Effects of Female Genital Mutilation among Maasai Women in Maternity Ward at Loitokitok Sub-County Hospital, Kenya. Obstetrics and gynecology international, 2018, 8418234. https://doi.org/10.1155/2018/8418234

[23] Odhiambo, A. (2020). Hrw.org. Tackling Kenya's Domestic Violence Amid COVID-19 Crisis; Lockdown Measures Increase Risks for Women and Girls. Retrieved from https://www.hrw.org/news/2020/04/08/tackling- 
kenyas-domestic-violence-amid-covid-19-crisis Accessed on 2nd September, 2020.

[24] Olson, J. S., Hummer, R. A., \& Harris, K. M. (2017). Gender and Health Behavior Clustering among U.S. Young Adults. Biodemography and social biology, 63(1), 3-20. https://doi.org/10.1080/19485565.2016.1262238

[25] Omara T. (2020). Antimalarial Plants Used across Kenyan Communities. Evidence-based complementary and alternative medicine: eCAM, 2020, 4538602. https://doi.org/10.1155/2020/4538602.

[26] Pakdamana, S. and Beina, A. (2014). Maasai Culture and its Effect on Sexual Health: A Field Study on the Disparities of Knowledge Within the Community, Journal of global health, Retrieved from https://www.ghjournal.org/maasai-culture-and-its-effect-on-sexual-healtha-field-study-on-the-disparities-of-knowledge-within-the-community/

[27] pngkey.com, (2020). Narokcounty Ginicoefficient - Narok County Map. Retrieved from https://www.pngkey.com/detail/u2w7y3y3w7i1a9o0_narokcountyginicoefficient-narok-county-map/ Accessed on 22nd August, 2020.

[28] Price, M., Hides, L., Cockshaw, W., Staneva, A. A., \& Stoyanov, S. R. (2016). Young Love: Romantic Concerns and Associated Mental Health Issues among Adolescent Help-Seekers. Behavioral sciences (Basel, Switzerland), 6(2), 9. https://doi.org/10.3390/bs6020009

[29] Ruggles S. (2010). Stem families and joint families in comparative historical perspective. Population and development review, 36(3), 563-577. https://doi.org/10.1111/j.1728-4457.2010.00346.x [30] Statisticshowto.com (2020). Research Assignments - Slovin's formulae: What is it and When do I use it - Statistics How to. Retrieved from https://www.statisticshowto.com/how-to-use-slovins-formula/ Accessed on 23rd July, 2020.

[31] Widman, L., Choukas-Bradley, S., Helms, S. W., \& Prinstein, M. J. (2016). Adolescent Susceptibility to Peer Influence in Sexual Situations. The Journal of adolescent health: official publication of the Society for Adolescent Medicine, 58(3), 323-329. https://doi.org/10.1016/j.jadohealth.2015.10.253

[32] Appendices: Questionnaire guide used 